First Peoples Child \& Family Review

A Journal on Innovation and Best Practices in Aboriginal Child Welfare Administration,

Research, Policy \& Practice

\title{
Utilization of the Canadian Incidence Study of Reported Child Abuse and Neglect in First Nations Child Welfare Agencies in Ontario
}

\author{
Lil Tonmyr, Susan Jack, Sandy Brooks, Betty Kennedy and Peter Dudding
}

Volume 4, Number 1, 2009

URI: https://id.erudit.org/iderudit/1069348ar

DOI: https://doi.org/10.7202/1069348ar

See table of contents

Publisher(s)

First Nations Child and Family Caring Society of Canada

ISSN

1708-489X (print)

2293-6610 (digital)

Explore this journal

Cite this article

Tonmyr, L., Jack, S., Brooks, S., Kennedy, B. \& Dudding, P. (2009). Utilization of the Canadian Incidence Study of Reported Child Abuse and Neglect in First Nations Child Welfare Agencies in Ontario. First Peoples Child \& Family Review, 4(1), 38-46. https://doi.org/10.7202/1069348ar

\section{Article abstract}

The goals of this study are: to examine the awareness and utilization of the Canadian Incidence Study of Reported Child Abuse and Neglect (CIS) and the Ontario Incidence Study of Reported Child Abuse and Neglect (OIS) by First Nations child welfare decision-makers in the child welfare policy development process in the Province of Ontario and; to identify ways of making the CIS/OIS more useful to First Nations decision makers. No previous study has focused on assessing the influence and impact that the CIS/OIS data have on policy development with this specific population.
Copyright $@$ Lil Tonmyr, Susan Jack, Sandy Brooks, Betty Kennedy, Peter Dudding, 2009
This document is protected by copyright law. Use of the services of Érudit (including reproduction) is subject to its terms and conditions, which can be viewed online.

https://apropos.erudit.org/en/users/policy-on-use/ 


\title{
Utilization of the Canadian Incidence Study of Reported Child Abuse and Neglect in First Nations Child Welfare Agencies in Ontario
}

\author{
Lil Tonmyra, Susan Jack ${ }^{\mathrm{b}}$, Sandy Brooks ${ }^{\mathrm{c}}$, Betty Kennedy ${ }^{\mathrm{d}}$, and Peter Duddinge
}

\author{
${ }^{a}$ MSW, PhD, Injury and Child Maltreatment Section, Health \\ Surveillance and Epidemiology Division, Public Health Agency of \\ Canada, Ottawa, Ontario \\ ${ }^{\mathrm{b}} \mathrm{RN}, \mathrm{PhD}$, School of Nursing, McMaster University, Hamilton, \\ Ontario, Canada \\ c BA, Research Assistant, McMaster University, Hamilton, Ontario, \\ Canada \\ ${ }^{\mathrm{d}}$ Executive Director, Association of Native Child and Family \\ Service Agencies of Ontario, Canada \\ ${ }^{\mathrm{e}}$ Executive Director, Child Welfare League of Canada, Ottawa, \\ Ontario, Canada
}

\section{Introduction}

The Canadian Incidence Study of Reported Child Abuse and Neglect (CIS) is a national public health surveillance system that captures data on five types of child maltreatment (neglect, emotional maltreatment, exposure to domestic violence, sexual and physical abuse) (Trocmé, Fallon et al., 2005). Surveillance is a systematic process of data collection, analysis and interpretation, and communication of information on key issues. The CIS surveillance system is set up to provide national estimates about the scope of investigated and substantiated child maltreatment within the Child Welfare System. It is the only source of national child maltreatment surveillance data in Canada.

Approximately one thousand child protection workers across Canada participate in the collection of valuable

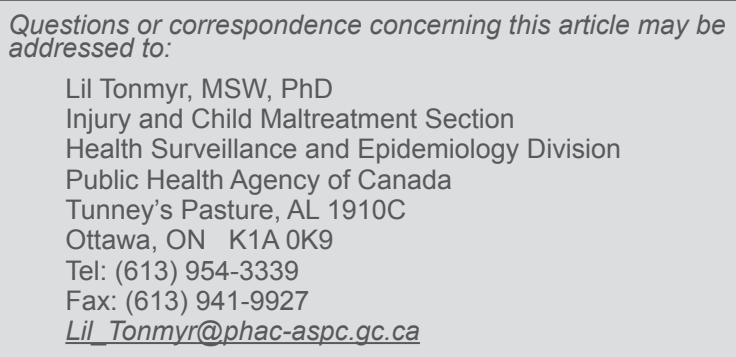

\begin{abstract}
The goals of this study are: to examine the awareness and utilization of the Canadian Incidence Study of Reported Child Abuse and Neglect (CIS) and the Ontario Incidence Study of Reported Child Abuse and Neglect (OIS) by First Nations child welfare decision-makers in the child welfare policy development process in the Province of Ontario and; to identify ways of making the CIS/OIS more useful to First Nations decision makers. No previous study has focused on assessing the influence and impact that the CIS/OIS data have on policy development with this specific population.
\end{abstract}

information on child maltreatment allegations reported to and investigated by a representative sample of child welfare agencies. This ambitious undertaking is the result of a partnership between child protection workers located in both First Nations and main stream agencies, researchers and provincial/territorial and federal governments. This partnership is, like child maltreatment, multi-sectoral and encompasses the social, health and justice spheres.

The CIS looks at information collected from each province and territory and incorporates it into descriptive statistics that describes the scope of the problem at the national level. However, some provinces such as Ontario have chosen to collect additional data (oversample) to obtain provincial estimates so that they can understand the magnitude and trends of child maltreatment within their own province. In Ontario, child maltreatment surveillance data have been collected since the 1993 Ontario Incidence Study of Reported Child Abuse and Neglect (OIS-1993) (Trocmé, McPhee, Kwan Tam, \& Hay, 1994). With the start of the CIS in 1998, the OIS has become a component of the larger national data collection activity. Since 1998, a growing number of First Nations child welfare agencies across the country have actively participated in the CIS. In the 2003 cycle, eight First Nations agencies were involved in the data collection process (Trocmé, Knoke, Shangreaux, 


\section{Acknowledgement}

This study was funded by the Centre of Excellence for Child and Youth Mental Health at the Children's Hospital of Eastern Ontario. Dr. Jack currently holds the Reproduction and Child Health New Investigator Personnel Award from the Institute of Human Development, Child and Youth Health, Canadian Institutes of Health Research. The authors gratefully acknowledge: the participants for providing information to this study; Corinne Fox for assisting in developing the interview guide; Cindy Blackstock, First Nations Child and Family Caring Society, and the three Journal reviewers for providing helpful comments of an earlier version of this paper.

Fallon, \& MacLaurin, 2005; Trocmé, MacLaurin, Fallon, Knoke, Pitman, \& McCormack, 2005). Although this convenience sample is only a fraction of delegated First Nations agencies across Canada, the FNCIS-2003 can be seen as a pilot stage where a purposeful effort has been to develop capacity across cycles - both in terms of research resources and in terms of First Nations community involvement. The First Nations data are included in the CIS general report but also in specific First Nations reports. The First Nations data are obtained form delegated agencies who provide services also to First Nations populations within their jurisdictions.

Data are collected on the following areas: type of child maltreatment; nature and extent of harm stemming from the maltreatment; source of the allegation; short term investigation outcomes; child and family characteristics; child functioning; agency and child protection worker information (Trocmé, Fallon, et al., 2005).

Changes to data collection between cycles are kept to a minimum to be able to compare changes over time. At the same time the surveillance system is receptive to emerging issues that need attention. Thus, the physical abuse measures were improved between the CIS-1998 and the CIS-2003. Based on the increase in emotional maltreatment and exposure to domestic violence captured by the CIS-2003, special attention will be paid to these issues in CIS-2009. In addition, the first cycle indicated the over-representation of First Nations children in the child welfare system. CIS-1998 data indicate that Aboriginal (First Nations, Inuit and Métis) children were placed in care more often than non-Aboriginal (9.9\% vs. 4.6\%) (Trocmé, Knoke, \& Blackstock, 2004). In subsequent cycles, efforts have been made to increase the number of First Nations child welfare agencies participating in the study to confirm and better understand the experiences of this population.

The CIS/OIS were developed to contribute evidence for planning and implementation of programs aimed at preventing child maltreatment and assisting children who have experienced child maltreatment. To accomplish these goals effectively, the data should be collected and disseminated in a timely manner. As with all surveillance systems, the CIS should detect changes in professional practice and monitor changes over time and place (Centers for Disease Control and Prevention, 2001; Stroup, 1992). To date, little is known about the utilization of CIS/OIS or the impact that this form of evidence has on child welfare policy developed to promote child health and social wellbeing.

Child welfare has, during the past few years, seen an increase in evidenced-based decision-making (EBD). EBD is a quest to obtain the best external evidence related to the client's issues, taking into account the specific individual in terms of the person's situation, values and preferences (Sackett, Rosenberg et al., 1996). Because of the cyclical nature of the CIS, it has a natural flow of phases: data collection, data analysis and dissemination. It provides an opportunity for reflections and improvements in each phase. In a Canadian child maltreatment surveillance context, the concept of dissemination is evolving from a passive to an interactive process (Jack \& Tonmyr, 2009). This knowledge transfer and exchange (KTE) process can be defined as a collaborative and interactive process which incorporates the interchange of different types of knowledge between researchers and decision-makers (Mitton, Adair, McKenzie, Patten \& Perry, 2007). Thus, KTE becomes an important concept influencing EBD.

The overall goal of this exploratory, qualitative research study is to examine the awareness and utilization of the CIS and OIS by First Nations child welfare decisionmakers at the local agency level in the child welfare policy development process in the Province of Ontario. No previous study has focused on assessing the influence and impact that the CIS/OIS data have on policy development with this specific population.

The specific study objectives are to:

1. Examine the awareness of the CIS/OIS by decisionmakers within First Nations child welfare agencies.

2. Explore the influence and impact of the CIS/OIS on First Nations child welfare policy.

3. Identify strategies for increasing the utility of CIS/OIS findings for First Nations decision makers.

\section{Methods}

This study is part of a larger EBD study in child welfare using both qualitative and quantitative research methods. The current study utilized information from First Nations agencies in Ontario. One First Nations member representing the Association of Native Child and Family Service Agencies of Ontario (ANCFSAO) collaborated 
with the research team in developing the interview guide and an additional First Nations representative from the agency participated in the interpretation of data. This study was conducted with a specific focus on understanding how the CIS/OIS public health surveillance data are utilized by senior decision-makers in Ontario First Nations agencies. The use of a case study approach enables us to move beyond quantitative findings describing if the CIS/OIS is used in policy development to explaining how and why it is or is not utilized. Case study has been suggested as a primary qualitative design that best assists in providing detailed information necessary for the identification of competing interests in decision making such as, availability of resources and values of stakeholders where the role of research evidence may be down played (Lavis, Ross, McLeod, \& Gildiner, 2003). Case study involves the study of a contemporary and contextualized phenomenon (Yin, 2003). It is a useful method to explore complex social interactions, when the investigators have limited control and when the boundaries between the phenomenon and the context in which it is situated are not well defined (Yin).

The ANCFSAO is an organization representing nine First Nations child welfare agencies in Ontario. As a mandate, members of ANCFSAO are committed to the development of and advocacy for culturally based child welfare policy and research for Aboriginal children living in Ontario (ANCFSAO, 2005). It is important to note that the limited number of FNCFSA's and the lack of staff within these organizations have to date precluded the development of policy units similar to those in mainstream agencies. Thus, much of the policy work falls to the Executive Director or front line child welfare workers in the local child welfare agency. This responsibility is added on to their other tasks. Three of the First Nations child welfare agencies in Ontario participated in this study. They were suggested by ANCFSAO. From within each organization, three key informants were identified using a process of purposeful sampling which refers to the recruitment of individuals who can provide rich, detailed and contextualized information about the phenomenon under study (Patton, 2002). In total nine key informants who were senior decision-makers within the First Nations child welfare agencies agreed to discuss their experiences and perceptions in two semistructured in-depth interviews.

Key informant interviews are used to efficiently gather information that would otherwise be unavailable to the researcher and to obtain an understanding or interpretation of the participant's culture (Gilchrist \& Williams 1999). A semi-structured in-depth interview guide derived from Dobbins, Ciliska, Cockerill, Barnsley \& DiCenso's (2002) KTE work in public health was developed to address questions regarding EBD in general child welfare practice and specifically about the CIS. See Table 1 for CIS/OIS selected questions.
Data analysis was conducted concurrently with data collection for the purpose of identifying themes requiring further exploration. The initial goal of the analysis was to construct an in-depth case study that is holistic and sensitive to context (Patton, 2002). Raw case data from all sources were collected and stored as electronic documents. The qualitative software program NVivo 7.0 was used to facilitate data storage, indexing, searching, and coding. A case record, a file of all raw data organized, classified and edited, was created for each site. In the early phases of analysis, selected interview transcripts were independently coded twice by different investigators to develop a coding scheme. This coding scheme was used to code all raw data, adapting it as new concepts emerged. Coded data was then further condensed into categories or themes.

All of the interviews, except one, were audio taped and transcribed verbatim. Six of the nine interviews were conducted over the phone. The remaining three were done face-to-face at the relevant First Nations child welfare agency. The first interviews lasted between 60-90 minutes. Within six to nine months of the initial interview a second interview lasting no longer than 30-45 minutes was conducted. The purpose of these follow-up interviews was to obtain comments on the accuracy of our interpretation of the data the participant shared in the initial interview. At the start of the second interviews, the participants were given a summary of their first interview. Subsequent questions dealt with clarifying or expanding upon this information and follow-up interviews varied with each respondent. Participants were provided with the opportunity to share additional insights about the issue at this time. Ethics approval was provided by McMaster University Research Ethics Board. Because the study required neither client involvement nor information about clients, no ethics approval was obtained from the individual child welfare agencies.

\section{Results}

Nine child welfare administrators representing three First Nations child welfare agencies located in rural or remote locations participated in this qualitative study. Five of these respondents have completed the second interview to date. Reasons for not participating in the second interview varied from the participant leaving the job to the demands of a very busy schedule. This sample of child welfare administrators included three Executive Directors, and six Directors of Service with program responsibilities. College or university degrees were obtained by the majority. Six respondents had a bachelor or a master's degree in social work. Their years of experience ranged from 6-16 years (mean 13 years) in child welfare and from less than 1-8 years (mean 4 years) in the present position. These respondents were in a unique position to comment 


\section{First Peoples Child \& Family Review, Volume 4, Number 1, 2008}

\section{Table 1: Selected Interview Guide - Questions Pertaining to the CIS/OIS}

Knowledge of Canadian Incidence Study of Reported Child Abuse and Neglect (CIS)/ Ontario Incidence Study of Reported Child Abuse and Neglect (OIS) Reports or Major Findings (ask all questions in regards to both CIS/OIS).

a. There is a Public Health Agency of Canada document called the Canadian Incidence Study of Reported Child Abuse and Neglect (CIS). Are you familiar with this document?

i. Have you seen or read the full version of the document?

ii. Have you seen or read any of the fact sheets associated with this document?

iii. If you are not familiar yourself with this document/fact sheet yourself, is there a person or position within your agency that is responsible for keeping abreast of current, relevant research evidence?

iv. May we contact that person? (Get contact information)

b. There is a similar document called the Ontario Incidence Study of Reported Child Abuse and Neglect (OIS). Are you familiar with this document?

v. Have you seen or read the full version of the document?

vi. Have you seen or read any of the fact sheets associated with this document?

vii. If you are not familiar yourself with this document/fact sheet yourself, is there a person or position within your agency that is responsible for keeping abreast of current, relevant research evidence?

viii. May we contact that person? (Get contact information)

If you are familiar with these documents,

c. Can you describe the Canadian Incidence Study of Reported Child Abuse and Neglect (CIS)/Ontario Incidence Study of Reported Child Abuse and Neglect (OIS)? What do you know about these national and provincial programs of surveillance?

d. How did you become aware of the CIS/OIS?

e. When was this?

f. Do you recall where you got the reports or fact sheets from?

g. What is your understanding about some of the key messages that have been circulated from the CIS/OIS?

h. What strategies have increased your awareness of CIS/OIS findings?

i. How could research evidence/ data be more usefully presented (within your agency and generally?)

Persuasion

a. Have you been influenced by the CIS/OIS when it comes to policy or decision making? If so, how?

b. Was there a particular feature(s) of the CIS/OIS that influenced your decision to use this data?

c. What characteristics of your organization influence the utilization of research evidence (in particular the CIS/OIS) in policy development?

d. What factors support or limit your individual ability to use research evidence in policy development? (i.e lack of computers, no access to library resources etc.)

e. What is in place to promote/support integration of research knowledge into your agency?

f. Is there a process in place to provide training around understanding and using research evidence?

g. If you were able to use this research evidence (CIS/OIS) to develop policy, would you have? Why or why not?

h. What role, if any, does the Child Welfare environment in Ontario play in the utilization of research evidence in policy development? (Current social climate)

Implementation

a. Are CIS/OIS findings conveyed to staff within your agency? What about other research findings?)

b. Based on your organizational chart, which levels of staff receive this information?

c. Does every unit in your agency receive this information? If not, what determines who receives the information? (Probe front line, supervisors etc.)

d. How is this done? (Probe staff/team meetings, email, memos, training days etc.)

e. For what purpose is this information conveyed?

f. What do you think has been the impact of sharing CIS/OIS information with staff in your agency? If it has not been shared, what impact do you think that had on staff?

Confirmation

a. Describe how OIS/CIS findings have been used or integrated into practice or policy development. (Probe for instrumental, conceptual and symbolic use. Conceptual? To provide enlightenment or insight about an issue, better understanding? Symbolic? Did you use it to defend or disprove a policy, propose a new policy based on the results? Instrumental? Did the key messages result in an immediate change to a policy or practice?

b. Has the data had an impact on decisions at the agency level? If so, what type? (Probe resource allocation/reallocation; maintain, discontinue or initiate programs/services; staff training)

c. Can you provide examples of policies developed on this research evidence?

d. Have you used CIS/OIS data in other ways? (Probe for sharing it with the community, other agencies, Councils or Boards)

e. What do you think the overall impact of the CIS/OIS data has been on your organization? How could this impact level be enhanced? What has been the impact of research data generally on your organization?

f. As the child welfare system is transforming in Ontario, can you discuss how CIS/OIS data have influenced or impacted this process? 


\section{Untilization of the Canadian Incidence Study of Reported Child Abuse and Neglect}

on the use of the CIS/OIS in their agencies due to their leadership roles.

There were several questions pertaining to the CIS/OIS in the interview guide (see Table 1). General information regarding EBD in First Nations child welfare agencies will be addressed in a separate publication. The CIS related questions addressed familiarity, access, utilization in terms of practice and policy development as well as suggestions for improved dissemination.

\section{Awareness of the CIS/OIS}

Just over half of respondents were aware of the CIS, leaving almost half who had never heard about the study. There were multiple ways that the CIS had come to their attention including circulation of the CIS report within the agency, presentation of the CIS data by a CIS research team member to the agency, respondent's participation in meetings that had highlighted the CIS findings, information from the ANCFSAO and involvement in the CIS data collection process. Participants identified that they had, or were aware that they could, access the CIS findings or fact sheets through the Ontario Ministry of Children and Youth Services (MCYS), the ANCFSAO or through a general search using Google.

Knowledge of Content and Perception of Quality of the Research

Among the five respondents aware of the CIS/OIS, knowledge of specific content was scarce. Only two of the respondents reported being aware that the CIS contained data pertaining to First Nations. One of these respondents knew the prevalence of various types of maltreatment reported for First Nations children and could compare these findings to mainstream agencies. Another individual identified that the CIS data confirmed his/her understanding of the extent of child maltreatment in his/her community, although this confirmation was disturbing. For instance, in one interview, the participant perceived the dissemination phase of the study quite negatively, because of the pain associated with seeing the actual data describing the reported rates of substantiated abuse and neglect within Canadian First Nations populations of children and the outcomes experienced by these children. However, it was appreciated that a well known researcher had come to their agency. In addition the opportunity to provide feedback was valued. The respondents indicated that they had high levels of understanding in regards to the abuse/neglect experiences of First Nations children but that seeing the final numbers of substantiated abuse was shocking when it was presented back in the form of a formal report. His/her feelings are exemplified by this quote:

"... someone is coming and telling me all this stuff and it's hitting you real hard because it's hurtful. It's impending. It's doom. It's hurtful, hurtful things."
Three had missed the information relating to First Nations children altogether and one was critical that the CIS did not meet their information needs, but would still consider participating in the CIS in the future in order to make the data more relevant.

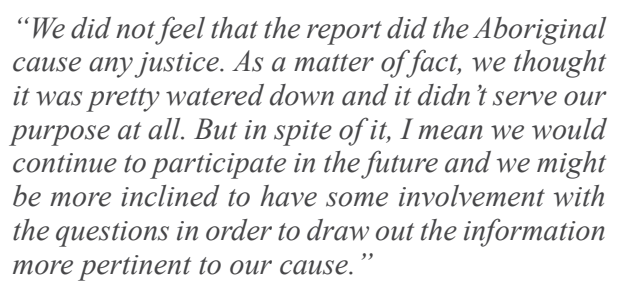
purpose at all. But in spite of it, I mean we would continue to participate in the future and we might be more inclined to have some involvement with the questions in order to draw out the information more pertinent to our cause."

Another respondent missed the inclusion of local data. The respondents who had no knowledge of the content, not surprisingly, had no opinion regarding quality.

\section{Utilization}

The questions regarding utilization addressed the CIS influence on policy development and impact on the agency. One respondent perceived that the CIS data had influenced policy changes at the level of the Ontario MCYS but that MCYS did not fully anticipate or study the consequences of their decisions and changes to policy on First Nations communities. Not all of these consequences were considered positive. As one respondent commented:

\footnotetext{
"...that data influenced a change of events within the child welfare secretariat...that impacted our agency and our community people, - and those two little girls that walked by right now - in a manner that affects our whole being and way of life. And [the researcher] might not think that [the] research was that important in the sense that it was used by policy makers within the secretariat to try to do the best interest for everybody but that 'everybody' doesn't always work for First Nations people and that's the sad part of it all."
}

One respondent was wary of use of the CIS in policy development at the Ministerial level, since it could be construed as justification of decisions already taken. However, another respondent did not think the CIS had been used this far. At the agency level the CIS data had confirmed the management's own assessment of the extent of various types of child maltreatment in their own communities. Considering that child neglect is the biggest problem in First Nations communities and not other types of maltreatment. These children have experienced more neglect due to poverty, poor housing and substance misuse, issues that have to be addressed at multiple levels including the individual, family and community and structural changes. The CIS validated the respondents own impressions that: 
"child welfare is more complex than just snatch and grab...it isn't about enforcement; it's about good social work."

One respondent would not use the CIS data at the agency level because the respondent felt that policy development at the agency level "is more intuitive, it is more experiential."

\section{Suggestions for Dissemination}

In terms of suggestions for the dissemination of findings emerging from the CIS, all of the respondents had ideas on how to improve effective communication of scientific data to their communities. It was reinforced that oral communication is the preferred approach rather than distribution of written reports. It was appreciated that members of the CIS research team had come back to the participating community to present the results of the study. The presentations of research findings should preferably be given in person but respondents were not unfamiliar with or opposed to using technology, such as the internet, video and audio tapes. The reporting back should be "interactive and fun," using visuals like PowerPoint. It was also suggested that presentation could be given at regional debriefings. One respondent stated:

"value for me comes from...our own people...I do believe there is value

[for First Nations] in research in mainstream system as well."

Another respondent acknowledged that two out of three researcher/research assistants that had been involved with CIS data collection came from First Nations communities.

Another idea that was expressed was the need for linking the CIS results to practical interventions. Child protection workers need to "understand how [the data] can be useful, about the practical implications." Research will only be useful if it is relevant and one of the key functions of child protection work is knowing how to intervene with clients.

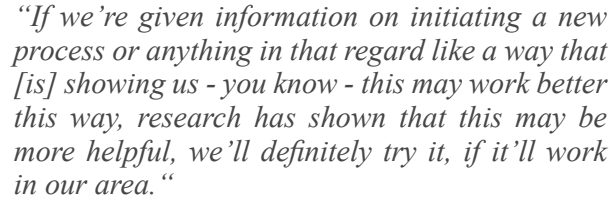

\section{Discussion}

The CIS is a major surveillance project that according to this study has only been marginally successful in reaching and being useful for First Nations agencies in Ontario. The findings from this study are limited by the small sample size of nine senior decision-makers within First Nations child welfare organizations from rural or remote locations. The geographic location of these agencies may have impeded decision-makers' abilities to develop networks with researchers and/or attend meetings or conferences where the CIS data had been promoted. Problems in accessing evidence were identified as a barrier to research utilization in mainstream agencies also (Jack, Dobbins, Tonmyr, Dudding, \& Brooks, 2009). It is important to note when the respondents had participated in the CIS, they were more knowledgeable both about CIS and research in general. This is not surprising since reports were sent by mail and email to participating agencies and face-to-face presentations were offered. Overall however, it is important to recognize that despite the small number of First Nations agencies in Ontario, First Nations participation in the CIS has improved since its inception at a national level. In CIS-1998, three First Nations agencies participated, in CIS-2003 eight agencies took part in the study and in CIS2009 it is planned that twenty First Nations agencies will be data collection sites. This increase will provide better and more detailed information on First Nations children and communities. CIS-2009 data may thus have more relevance to First Nations child welfare agencies, hopefully increasing its usage. It has also been recognized after CIS2003 that all components of surveillance (data collection, data analysis and dissemination) take considerable resources (Jack \& Tonmyr, 2009). Dissemination of findings to First Nations organizations, particularly those in rural or remote locations that value face-to-face oral communication requires resources dedicated for researchers to travel long distances to the home organizations.

As the field of knowledge translation and exchange evolves, there will be in some contexts greater expectations on researchers, who are often perceived as credible messengers (Lavis et al, 2003) to assume greater responsibilities for disseminating information using strategies and communication channels beyond traditional means of publications and conferences (Denis, Lehoux \& Champagne, 2004). This requirement to actively participate in KTE activities places a great responsibility and burden on many scientists primarily engaged in the production of evidence. Additionally, some researchers may lack the knowledge, skill or inclination to effectively disseminate evidence effectively to different target audiences. In relation to the dissemination of the CIS, a national surveillance program, with multiple different target audiences, there is then a responsibility for multiple individuals and organizations external to the primary research teams to assume the intensive activity of disseminating findings.

One way of improving the use of research evidence in the decision-making process is for decision makers and researchers to work together in both the production of knowledge and dissemination phase (Innaer, Vist, Trommald \& Oxmann, 2002; Tonmyr, De Marco, Hovdestad \& Hubka, 2004). This may be even more important in First Nations communities. However, this is challenging 
considering the varied response to the CIS. One of the respondents focused on the numbers and statistics reported in the CIS meanwhile others were emotional in their data interpretation, i.e., crying when thinking of First Nations children who have experienced maltreatment. Anticipating these diverse responses may assist in dissemination. For instance, it has been suggested from clinical social work literature that it is important to understand and assess if a decision is based on "head" or "heart" activity in order to meet the needs of children. Since, humans are not automatons, utilization of evidence is influenced by a range of factors (Howarth, 2007).

Taking these points to heart, changes have been made between cycles of data collection regarding First Nations content. In CIS-2003, questions were added regarding the child's Aboriginal status (First Nations status; First Nations non-status; Métis; and Inuit). The CIS-2009 questionnaire will be changed to include the following questions: caregiver attended residential school; grandparent attended residential school; band housing; and referral to alternative dispute resolution program (e.g., Aboriginal circle). These changes took place after consultations with First Nations representatives and were seen as important elements in creating a knowledge base for First Nations child welfare agencies. In addition, a First Nations steering committee was formed in September, 2007 with representation from across the country. It is also important to note that First Nations representatives have since the inception of the CIS been represented on the CIS steering committee and been involved in all phases of the CIS. There has been many First Nations and non First Nations champions for inclusion and better First Nations CIS data in the various cycles. This committee has communicated on a regular basis to guide the CIS in important questions such as First Nations Ownership, Control, Access and Possession over the data (First Nations Centre, 2007).

One identified limitation of the CIS was the need for practical intervention data. Clearly the overall purpose or function of surveillance data in general, and the CIS in particular, have not been well communicated. The primary purpose of the CIS and other surveillance system is to describe the problem, estimate the magnitude of the problem and analyze trends. Another identified limitation was the need for local data, which was also echoed in main stream agencies in Ontario (Jack et al., 2009). This limitation of the data has been recognized (Trocmé, Fallon et al., 2005) and initial discussions have started on how to improve local data. In the meantime the national level data can still useful at the local level. Although the gap between national problems and local situations is wide, clearly more effort is needed to:

- Convey how the two levels are linked;
- Compare national level data to local agency statistics to question the local practice and allocate resources appropriately; and

- Show how surveillance information and relevant research findings can be woven together to help develop useful strategies for local First Nations communities.

Albeit not well articulated, respondents seemed to have expectations that the CIS would illuminate strategies for prevention and intervention. However, other types of research are best suited to explore and provide this type of knowledge that can complement surveillance findings. The role of surveillance data is just to provide pointers and indications of where targeted research efforts are needed.

It is encouraging that CIS data may influence the policy debate at the provincial level. It was perceived that the CIS data had influenced policy changes in Ontario, while well intended, some of thesechanges havehadunanticipatedimpact on First Nations communities. Increased communication and consultation between policy makers at the Ministry level and First Nations decision makers would be beneficial to all parties. CIS data can serve as a source of background information to policy development. For instance, CIS data found no differences in placement of Aboriginal children compared to non Aboriginal children when aforementioned hard ships such as poverty and drug abuse were considered (Trocmé, Knoke, \& Blackstock, 2004).

It is also important to note that although CIS data have only started to impact policy making in Ontario and the rest of the country. The national level First Nations CIS data have been the foundation on which to challenge discrepancies in funding between First Nations and mainstream child welfare agencies. This has been acknowledged by the Auditor General (Office of the Auditor General of Canada, 2009). The CIS data has also been used in the complaint field at the Canadian Human Rights Commission by the Assembly of First Nations and the First Nations Child and Family Caring Society alleging that Canada violates child welfare legislation and the Charter of Rights and Freedoms and that First Nations children are receiving unequal benefit (Blackstock, 2009).

This research project was undertaken in part to help direct improvements to the CIS/OIS. The results clearly show that the CIS needs to be better disseminated in First Nations communities and the innovative methods that were suggested by the respondents need to be implemented when possible. The idea of using technology, such as video conferencing, to allow remote presentation of research data, and the openness of First Nations communities to consider this method of information sharing needs to be considered as this would allow access to other experts without the cost of face-to-face meetings. The visits from a representative of the research team in participating agencies were seen as positive and were well received. However, these efforts 
need to be complemented by other strategies. For instance, it is important to engage a respected and knowledgeable community member (e.g., elder) to build on localized and culturally appropriate knowledge. These community members may be able to illuminate links between the local situation and the CIS findings. In addition, through technical assistance, such as video conferencing, a dialogue may be initiated with respected experts outside the immediate community. These experts could, for instance, include members of the First Nations CIS Steering Committee.

Although this study is an important first step in understanding the utilization of the CIS by senior decision makers in First Nations agencies the data suffers from two limitations. The first is the small number of First Nations child welfare agencies in Ontario and the second is the lack of generalizability of findings outside of remote locations in Ontario.

Further research is warranted regarding EBD making in First Nations agencies. The qualitative interviews will assist in providing detailed descriptive information about how EBD making is used and barriers to its use in First Nations communities. Meanwhile, the quantitative data stemming from the second phase of this EBD study will provide additional knowledge through providing an overview of barriers and facilitators to the use of EBD making in Ontario. Considering the different organizational structures and the limited number of First Nations child welfare agencies in Ontario, a survey of First Nations agencies across the country would be desirable for a better understanding of the utility of the CIS.

\section{Conclusion}

This research project has been the first study in Canada that has systematically analyzed the utilization of the CIS/OIS in First Nations communities. It identified some fundamental challenges for KTE. Although many respondents were unaware of the CIS/OIS, those who had participated in the CIS knew the data better. All respondents assisted in providing insight into the identification of strategies for making the data more useful to First Nations child welfare agencies, through for instance linking the CIS data to practical interventions. It also provided input for more effective dissemination of the findings through the use of face-to face meetings and technological interactive means.

\section{References}

Association of Native Child and Family Service Agencies of Ontario (2002). Retrieved December 16, 2005 from http://www. nativecfs.org.

Blackstock, C. (2009). Reconciliation means not saying sorry twice: Lessons from child welfare in Canada. In: The Aboriginal Healing Foundation, Castellano, MB., Archibald, L. and DeGagné M. From Truth to Reconciliation, Transforming the Legacy of Residential Schools. Ottawa: Aboriginal Healing Foundation.

Centers for Disease Control and Prevention, Guidelines Working Group (2001). Updated guidelines for evaluating public health surveillance systems. $M M W R, 50$ (RR13), 1-35.

Denis, J., Lehoux, P., \& Champagne, F. (2004). A knowledge utilization perspective on fine-tuning dissemination and contextualizing knowledge. In L. Lemieux-Charles \& F. Champagne (Eds.), Using knowledge and evidence in health care: Multidisciplinary perspectives (pp. 18-40). Toronto, ON: University of Toronto Press.

Dobbins, M., Ciliska, D., Cockerill, R., Barnsley, J., \& DiCenso, A. (2002). A framework for the dissemination and utilization of research for health-care policy and practice. The Online Journal of Knowledge Synthesis for Nursing, 9, Document 7.

First Nations Centre. (2007). OCAP: Ownership, Control, Access and Possession. Sanctioned by the First Nations Information Governance Committee, Assembly of First Nations. Ottawa: National Aboriginal Health Organization.Retrieved July 16, 2009 from http://www.naho.ca/firstnations/english/documents/FNC-OCAP 001.pdf.

Gilchrist, V.J., \& Williams, R.L. (1999). Key informant interviews. In B. Crabtree \& W. Miller (Eds.), Doing qualitative research (2nd ed) (pp. 71-88). Thousand Oaks: Sage.

Horwath, J. (2007). The Missin Assessment Domain: Personal, Professional and Organisational Factors Influencing Professional Judgment when Identifying and Referring Child Neglect. British Journal of Social Work, 27:1285-1303.

Innvær, S., Vist, G., Trommald, M., \& Oxman, A. (2002). Health policy-makers' perceptions of their use of evidence: A systematic review. Journal of Health Services Research \& Policy, 7, 239-244.

Jack, S., Dobbins, M., Tonmyr, L., Dudding, P., \& Brooks, S. (2009). Factors influencing evidence based policy and research utilization by child welfare administrators. Submitted.

Jack, S., \& Tonmyr, L. (2009). Knowledge transfer and exchange: Disseminating Canadian child maltreatment surveillance findings to decision makers. Child Indicators Research, 1(1), 51-64.

Lavis, J.N., Robertson, D., Woodside, J.M., McLeod, C.B., Abelson, J., and the Knowledge Transfer Study Group (2003). How can research organizations more effectively transfer research knowledge to decision makers? The Millbank Quarterly, 81, 221-248.

Lavis, J., Ross, S., McLeod, C., \& Gildiner, A. (2003). Measuring the impact of health research. Journal of Health Services Research and Policy, 8, 165-170.

Mitton, C., Adair, C.E., McKenzie, E., Patten, S.B., \& Perry, B.W. (2007). Knowledge transfer and exchange: Review and synthesis of the literature. The Milbank Quarterly, 85, 729-768.

Office of the Auditor General of Canada (2009). Report of the Auditor General of Canada to the Legislative Assembly 


\section{Untilization of the Canadian Incidence Study of Reported Child Abuse and Neglect}

of Nunavut, Nunavut Housing Corporation. Ottawa. Retrieved 8 July 2009 from http://www.oag-bvg.gc.ca/internet/ docs $/ 200905$ nhe e.pdf.

Patton, M.Q. (2002). Qualitative research \& evaluation methods (3rd ed.). Thousand Oaks, CA: Sage.

Sandelowski, M. (1995). Sample size in qualitative research. Research in Nursing and Health, 18, 179-183.

Stroup, D.F. (1992). Surveillance data for policy: A national and state approach. $M M W R, 41$ (Suppl), 135-141.

Tonmyr, L., De Marco, R., Hovdestad, W.E., \& Hubka, D. (2004). Policy makers' perspectives on the utility of a national study of child maltreatment. Child Maltreatment, 9, 304-308.

Trocmé, N., Fallon, B., MacLaurin, B., Daciuk, J., Felstiner, C., Black, T., Tonmyr, L., Blackstock, C., Barter, K., Turcotte, D., \& Cloutier, R. (2005). Canadian incidence study of reported child abuse and neglect-2003: Major findings. Ottawa, ON: Minister of Public Works and Government Services Canada.

Trocmé, N., Knoke, D., \& Blackstock, C. (2004). Pathways to overrepresentation of aboriginal children in Canada's child welfare system. Social Services Review, 8(4);577-601.
Trocmé, N., Knoke, D., Shangreaux, B., Fallon, B., \& MacLaurin, B. (2005). The experience of First Nations children coming into contact with the child welfare system in Canada: The Canadian Incidence Study of Reported Child Abuse and Neglect. In First Nations Child \& Family Caring Society of Canada, Wen: De: We are Coming to the Light of Day. Ottawa, ON: First Nations Child and Family Caring Society of Canada: p. 60-86.

Trocmé, N., MacLaurin, B., Fallon, B., Knoke, D., Pitman, L., \& McCormack, M. (2005). Understanding the overrepresentation of First Nations children in Canada's child welfare system: An analysis of the Canadian Incidence Study of Reported Child Abuse and Neglect (CIS-2003). Toronto: Centre of Excellence for Child Welfare.

Trocmé, N., McPhee, D., Kwan Tam, K. \& Hay, T. (1994): Ontario incidence study of reported child abuse and neglect. Final report. Toronto, Ontario: The Institute for the Prevention of Child Abuse.

Yin, R.K. (2003). Case study research: Design and methods (3rd ed.). Thousand Oaks, CA: Sage. 